\title{
Applications of Higher-Order Optimal Newton Secant Iterative Methods in Ocean Acidification and Investigation of Long-Run Implications of $\mathrm{CO}_{2}$ Emissions on Alkalinity of Seawater
}

\author{
D. K. R. Babajee ${ }^{1}$ and V. C. Jaunky ${ }^{2}$ \\ ${ }^{1}$ Scientific \& Academic Research Council, African Network for Policy Research \& Advocacy for Sustainability, Midlands, Mauritius \\ ${ }^{2}$ Department of Business Administration, Technology and Social Sciences, Luleå University of Technology, SE-971 87 Luleå, Sweden \\ Correspondence should be addressed to V. C. Jaunky; vishal.jaunky@ltu.se
}

Received 3 April 2013; Accepted 4 May 2013

Academic Editors: C.-H. Lien and F. Tadeo

Copyright (C) 2013 D. K. R. Babajee and V. C. Jaunky. This is an open access article distributed under the Creative Commons Attribution License, which permits unrestricted use, distribution, and reproduction in any medium, provided the original work is properly cited.

\begin{abstract}
The Newton secant method is a third-order iterative nonlinear solver. It requires two function and one first derivative evaluations. However, it is not optimal as it does not satisfy the Kung-Traub conjecture. In this work, we derive an optimal fourth-order Newton secant method with the same number of function evaluations using weight functions and we show that it is a member of the King family of fourth-order methods. We also obtain an eighth-order optimal Newton-secant method. We prove the local convergence of the methods. We apply the methods to solve a fourth-order polynomial arising in ocean acidifications and study their dynamics. We use the data of $\mathrm{CO}_{2}$ available from the National Oceanic and Atmospheric Administration from 1959 to 2012 and calculate the $\mathrm{pH}$ of the oceans for these years. Finally we further investigate the long-run implications of $\mathrm{CO}_{2}$ emissions on alkalinity of seawater using fully modified ordinary least squares (FMOLS) and dynamic OLS (DOLS). Our findings reveal that a one-percent increase in $\mathrm{CO}_{2}$ emissions will lead to a reduction in seawater alkalinity of 0.85 percent in the long run.
\end{abstract}

\section{Introduction}

Recent advancements in the study of higher-order multipoint methods have made this field of research very active. Much literature on the multipoint Newton-like methods for function of one variable and their convergence analysis can be found in [1] and the historical developments of the methods in [2]. Newton secant method is a third-order two-point method and it was rediscovered in [3] as a leapfrog Newton method. However, it is not optimal because the order of an optimal method with 3 function evaluations should be 4 according to the Kung-Traub conjecture. In this work, we derive an optimal fourth-order Newton secant method with same number of function evaluations using weight functions and we show that it is a member of the King family of fourth-order methods. We also obtain an eighthorder optimal Newton secant method. We prove the local convergence of the methods. We apply the methods to solve a fourth-order polynomial arising in ocean acidifications and study their dynamics. We use the data of $\mathrm{CO}_{2}$ available from the National Oceanic and Atmospheric Administration from 1959 to 2012 and calculate the $\mathrm{pH}$ of the oceans for these years. Finally, we further investigate the long-run implications of $\mathrm{CO}_{2}$ emissions on alkalinity of seawater using fully modified ordinary least squares (FMOLS) and dynamic OLS (DOLS).

\section{Developments of the Methods}

Let $x_{n+1}=\psi\left(x_{n}\right)$ define an iterative function (IF).

Definition 1 (see [4]). If the sequence $\left\{x_{n}\right\}$ tends to a limit $x^{*}$ in such a way that

$$
\lim _{n \rightarrow \infty} \frac{x_{n+1}-x^{*}}{\left(x_{n}-x^{*}\right)^{p}}=C
$$

for $p \geq 1$, then the order of convergence of the sequence is said to be $p$, and $C$ is known as the asymptotic error constant. 
If $p=1, p=2$, or $p=3$, then the convergence is said to be linear, quadratic, or cubic, respectively.

Let $e_{n}=x_{n}-x^{*}$, and then the relation

$$
e_{n+1}=C e_{n}^{p}+O\left(e_{n}^{p+1}\right)=O\left(e_{n}^{p}\right) .
$$

is called the error equation. The value of $p$ is called the order of convergence of the method.

Definition 2 (see [5]). The efficiency index is given by

$$
\mathrm{EI}=p^{1 / d}
$$

where $d$ is the total number of new function evaluations (the values of $f$ and its derivatives) per iteration.

Let $x_{n+1}$ be determined by new information at $x_{n}, \phi_{1}\left(x_{n}\right), \ldots, \phi_{i}\left(x_{n}\right), i \geq 1$.

No old information is reused. Thus,

$$
x_{n+1}=\psi\left(x_{n}, \phi_{1}\left(x_{n}\right), \ldots, \phi_{i}\left(x_{n}\right)\right) .
$$

Then $\psi$ is called a multipoint IF without memory.

Kung-Traub Conjecture (see [6]). Let $\psi$ be an IF without memory with $d$ evaluations. Then

$$
p(\psi) \leq p_{\text {opt }}=2^{d-1},
$$

where $p_{\text {opt }}$ is the maximum order.

The Newton (also called Newton-Raphson) IF (2nd NR) is given by

$$
\psi_{2 \text { nd NR }}(x)=x-u(x), \quad u(x)=\frac{f(x)}{f^{\prime}(x)} .
$$

The 2nd NR IF is one-point IF with 2 function evaluations and it satisfies the Kung-Traub conjecture $d=2$.

The Halley IF ( $3 \mathrm{rd} \mathrm{Hal}$ ) is given by

$$
\psi_{3 \text { rd Hal }}(x)=x-\frac{u(x)}{1-c_{2}(x) u(x)}, \quad c_{2}(x)=\frac{f^{\prime \prime}(x)}{2 f^{\prime}(x)} .
$$

It is one-point IF with 3 function evaluations and $\mathrm{EI}_{3 \mathrm{rd} \mathrm{Hal}}=$ $1.44>\mathrm{EI}_{2 \text { nd NR }}=1.41$. However, we need to calculate the second derivatives which can be computationally expensive for complex functions. A remedy to this is the Newton-secant IF (3rd NS) which can be written as

$$
\psi_{3 \mathrm{rd} \mathrm{NS}}(x)=x-\frac{f(x)}{f(x)-f\left[\psi_{2 \mathrm{nd} \mathrm{NR}}(x)\right]} u(x) .
$$

It has the same efficiency as the 3 rd Hal IF but it requires $2 f$ and $1 f^{\prime}$ evaluations, hence no second derivatives, and is a also variant of $3 \mathrm{rd}$ Hal IF [7]. However, it does not satisfy the Kung-Traub conjecture. In this work, we develop a fourthorder Newton-secant IF with 3 functions evaluations using weight functions. The $3 \mathrm{rd}$ NS's IF can be written as

$$
\psi_{3 \mathrm{rd} \mathrm{NS}}(x)=x-u(x) \frac{1}{1-t_{1}}, \quad t_{1}=\frac{f\left[\psi_{2 \mathrm{nd} \mathrm{NR}}(x)\right]}{f(x)} .
$$

The 4th NS IF can be given by

$$
\psi_{4 \text { th NS }}(x)=x-u(x) \frac{1+t_{1}^{2}}{1-t_{1}} \text {. }
$$

Since $\mathrm{EI}_{4 \text { th NS }}=4^{1 / 3}=1.59$, the 4 th NS has a higher efficiency index. It is remarkable by just multiplying the last term of (9) by the weight function, $1+t_{1}{ }^{2}$, and we could increase the order from 3 to 4 . This IF is similar to the member $\beta=1$ of the one-parameter King family of fourth-order IF [8] given by

$$
\psi_{4 \mathrm{th} \mathrm{FK}}(x)=\psi_{2 \mathrm{nd} \mathrm{NR}}(x)-\frac{f\left(\psi_{2 \mathrm{nd} \mathrm{NR}}(x)\right)}{f^{\prime}(x)} \frac{1+\beta t_{1}}{1+(\beta-2) t_{1}} .
$$

Based on King-type family higher-order IFs [9], an eighthorder 8th NS IF can be given by

$$
\psi_{8 \text { th NS }}(x)=x-\frac{1}{f^{\prime}(x)}\left(\frac{1+t_{1}+1.5 t_{1}^{2}}{1-t_{1}+0.5 t_{1}^{2}}+4 t_{2}+t_{3}\right) \text {, }
$$

where

$$
t_{2}=\frac{f\left(\psi_{4 \mathrm{th} \mathrm{NS}}(x)\right)}{f(x)}, \quad t_{3}=\frac{f\left(\psi_{4 \mathrm{th} \mathrm{NS}}(x)\right)}{f\left(\psi_{2 \mathrm{nd} \mathrm{NR}}(x)\right)} .
$$

The 8th NS IF is an optimal IF which satisfies the Kung-Traub conjecture with $\mathrm{EI}_{8 \text { th NS }}=5^{1 / 4}=1.68$ which is the highest efficiency index among all IFs considered in this work.

\section{Convergence Analysis}

Theorem 3. Let a sufficiently smooth function $f: D \subset \mathbb{R} \rightarrow$ $\mathbb{R}$ have a simple root $x^{*}$ in the open interval $D$. Then the 4 th NS IF (10) is of local fourth-order convergence and the 8th NS IF (12) is of local eighth-order convergence.

Proof. Let $c_{j}=f^{(j)}\left(x^{*}\right) / j ! f^{\prime}\left(x^{*}\right), j=2,3,4$.

Using the Taylor series and the symbolic software such as, Maple we have

$$
\begin{gathered}
f(x)=f^{\prime}\left(x^{*}\right)\left[e_{n}+c_{2} e_{n}^{2}+c_{3} e_{n}^{3}+c_{4} e_{n}^{4}+\cdots\right], \\
f^{\prime}(x)=f^{\prime}\left(x^{*}\right)\left[1+2 c_{2} e_{n}+3 c_{3} e_{n}^{2}+4 c_{4} e_{n}^{3}+\cdots\right],
\end{gathered}
$$

so that

$$
\begin{aligned}
u(x)= & e_{n}-c_{2} e_{n}^{2}+2\left(c_{2}^{2}-c_{3}\right) e_{n}^{3} \\
& +\left(7 c_{2} c_{3}-4 c_{2}^{3}-3 c_{4}\right) e_{n}^{4}+\cdots, \\
\psi_{2 \text { nd NR }}(x)-x^{*}= & c_{2} e_{n}^{2}-2\left(c_{2}^{2}-c_{3}\right) e_{n}^{3} \\
& -\left(7 c_{2} c_{3}-4 c_{2}^{3}-3 c_{4}\right) e_{n}^{4}+\cdots .
\end{aligned}
$$

Now, the Taylor expansion of $f(y)$ about $x^{*}$ gives

$$
\begin{aligned}
f(y)= & f^{\prime}\left(x^{*}\right) \\
& \times\left[\left(y-x^{*}\right)+c_{2}\left(y-x^{*}\right)^{2}\right. \\
& \left.\quad+c_{3}\left(y-x^{*}\right)^{3}+c_{4}\left(y-x^{*}\right)^{4}+\cdots\right] .
\end{aligned}
$$


Using (14), (18), and (17), we have

$$
\begin{aligned}
t_{1}= & \frac{f\left[\psi_{2 \mathrm{ndNR}}(x)\right]}{f(x)} \\
= & c_{2} e_{n}+\left(2 c_{3}-3 c_{2}{ }^{2}\right) e_{n}^{2} \\
& +\left(3 c_{4}-10 c_{2} c_{3}+8 c_{2}^{3}\right) e_{n}^{3} \\
& +\left(-14 c_{2} c_{4}+37 c_{3} c_{2}{ }^{2}-20 c_{2}{ }^{4}-8 c_{3}{ }^{2}+4 c_{5}\right) e_{n}^{4}+\cdots,
\end{aligned}
$$

so that by using computer algebra software such as Maple we get

$$
\begin{gathered}
\psi_{3 \text { th NS }}(x)-x^{*}=c_{2}{ }^{2} e_{n}^{3}+\cdots \\
\psi_{4 \text { th NS }}(x)-x^{*}=c_{2}\left(-c_{3}+3 c_{2}^{2}\right) e_{n}^{4}+\cdots .
\end{gathered}
$$

Similarly, we have

$$
\begin{aligned}
t_{2}= & c_{2}\left(-c_{3}+3 c_{2}^{2}\right) e_{n}^{3} \\
& +\left(-2 c_{2} c_{4}-2 c_{3}^{2}+21 c_{3} c_{2}^{2}-21 c_{2}^{4}\right) e_{n}^{4}+\cdots \\
t_{3}= & \left(-c_{3}+3 c_{2}^{2}\right) e_{n}^{2} \\
& +\left(-2 c_{4}+12 c_{2} c_{3}-12 c_{2}^{3}\right) e_{n}^{3}+\cdots
\end{aligned}
$$

so that finally we get

$$
\begin{aligned}
& \psi_{8 \text { th NS }}(x)-x^{*} \\
& =\left(\frac{1}{2} c_{2}\left(-c_{3}+3 c_{2}{ }^{2}\right)\left(65 c_{2}{ }^{4}-34 c_{3} c_{2}{ }^{2}+2 c_{2} c_{4}+2 c_{3}{ }^{2}\right)\right) e_{n}^{8} \\
& \quad+\cdots
\end{aligned}
$$

\section{Ocean Acidification}

4.1. Introduction [2]. The accumulation of greenhouse gases (GHGs) in the Earth's atmosphere is now a major topic of discussion to anticipate changes in the Earth's climate. The GHGs cause a reduction in the reradiation of energy from the Sun back into the outer space. Since less energy leaves the Earth's atmosphere, heating of the atmosphere results as a manifest in a temperature rise [12]. This temperature rise, the so-called global warming, is in turn a driving force for climate change. $\mathrm{CO}_{2}$ is the major GHG, with increasing levels primarily from the burning of fossil fuels. Thus, changes in the $\mathrm{CO}_{2}$ level or concentration in the Earth's atmosphere are of paramount importance in understanding anticipated warming and climate change. A second aspect of $\mathrm{CO}_{2}$ accumulation in the atmosphere that is not as generally recognized and appreciated as temperature rise is the accumulation of carbon (from $\mathrm{CO}_{2}$ ) in the oceans that leads to ocean acidification. $\mathrm{CO}_{2}$ dissolves in ocean water and undergoes a series of chemical changes that ultimately leads to increased hydrogen ion concentration, denoted subsequently as $\left[\mathrm{H}^{+}\right]$, and thus acidification (see $[12,13])$. This increase in $\left[\mathrm{H}^{+}\right]$is manifest as a decrease in $\mathrm{pH}$; note that $\left[\mathrm{H}^{+}\right]$and $\mathrm{pH}$ move in opposite directions due to the following basic relation:

$$
\mathrm{pH}=-\log _{10}\left[\mathrm{H}^{+}\right] \text {. }
$$

Ocean acidification is the name given to the ongoing decrease in the $\mathrm{pH}$ of the Earth's oceans, caused by their uptake of anthropogenic carbon dioxide from the atmosphere [14]. Between 1751 and 1994, surface ocean $\mathrm{pH}$ is estimated to have decreased from approximately 8.179 to 8.104 (a change of -0.075 ) [15]. A decrease in ocean $\mathrm{pH}$ of 0.1 units corresponds to a $30 \%$ increase in the concentration of $\mathrm{H}^{+}$in seawater, assuming that alkalinity and temperature remain constant $[16$, p. 406]. There is about fifty times as much carbon dissolved in the oceans in the form of $\mathrm{CO}_{2}$ and carbonic acid, bicarbonate, and carbonate ions as that in the atmosphere. The oceans act as an enormous carbon sink and have taken up about a third of $\mathrm{CO}_{2}$ emitted by human activity [17]. Most of the $\mathrm{CO}_{2}$ taken up by the ocean forms carbonic acid in equilibrium with bicarbonate and carbonate ions. Some is consumed in photosynthesis by organisms in the water, and a small proportion of that sinks and leaves the carbon cycle. Increased $\mathrm{CO}_{2}$ in the atmosphere has led to decreasing alkalinity of seawater and there is concern that this may adversely affect organisms living in the water. In particular, with decreasing alkalinity, the availability of carbonates for forming shells decreases [18, p. 125], although there is evidence of increased shell production by certain species under increased $\mathrm{CO}_{2}$ content [19].

4.2. Ocean Chemistry [2]. We begin with $\mathrm{CO}_{2}$ dissolving in $\mathrm{H}_{2} \mathrm{O}$ to form carbonic acid, $\mathrm{H}_{2} \mathrm{CO}_{3}$ as

$$
\mathrm{CO}_{2}+\mathrm{H}_{2} \mathrm{O} \rightleftharpoons \mathrm{H}_{2} \mathrm{CO}_{3} \text {. }
$$

The double arrow $\rightleftharpoons$ denotes a reversible chemical reaction (a reaction that can proceed either forward to produce $\mathrm{H}_{2} \mathrm{CO}_{3}$ or backward to produce $\mathrm{CO}_{2}$ and $\mathrm{H}_{2} \mathrm{O}$ ).

A common convention is to take $\left[\mathrm{CO}_{2}\right]$ as the dissolved $\mathrm{CO}_{2}$, denoted as $\left[\mathrm{CO}_{2}\right]_{\mathrm{aq}}$, plus the carbonic acid $\left[\mathrm{H}_{2} \mathrm{CO}_{3}\right]_{\mathrm{aq}}$.

Carbonic acid is a weak acid which in turn dissociate into bicarbonate ions, $\mathrm{HCO}_{3}^{-}$, as

$$
\mathrm{H}_{2} \mathrm{CO}_{3} \rightleftharpoons \mathrm{H}^{+}+\mathrm{HCO}_{3}^{-} \text {. }
$$

Bicarbonate ions in turn dissociates into carbonate ions, $\mathrm{CO}_{3}^{2-}$

$$
\mathrm{HCO}_{3}^{-} \rightleftharpoons \mathrm{H}^{+}+\mathrm{CO}_{3}^{2-} \text {. }
$$

The reactions (25) and (26) produce hydrogen ions and therefore contribute to acidification.

$\mathrm{H}_{2} \mathrm{O}$ also dissociates to produce hydrogen ions as

$$
\mathrm{H}_{2} \mathrm{O} \rightleftharpoons \mathrm{H}^{+}+\mathrm{OH}^{-} \text {. }
$$

Additionally, boron hydroxide in seawater dissociates to produce hydrogen ions as

$$
\mathrm{B}(\mathrm{OH})_{3}+\mathrm{H}_{2} \mathrm{O} \rightleftharpoons \mathrm{H}^{+}+\mathrm{B}(\mathrm{OH})_{4}^{-} \text {. }
$$


In this work, we do not consider other compounds in the oceans that also dissociate to produce hydrogen ions. We explain how to compute $\left[\mathrm{H}^{+}\right]$and $\mathrm{pH}$ from the reactions (24) to (28). For the following analysis, we use the equilibrium constants of Bacastow and Keeling [20] expressed in the units of moles/litre. The relation between gaseous and liquid $\mathrm{CO}_{2}$ is

$$
K_{0}=\frac{\left[\mathrm{CO}_{2}\right]}{P_{t}}=3.347(-5),
$$

where $\left[\mathrm{CO}_{2}\right]$ is the sum of the dissolved $\mathrm{CO}_{2}$ and carbonic acid and $P_{t}$ is the gas phase $\mathrm{CO}_{2}$ partial pressure in ppm measured by the National Oceanic and Atmospheric Administration (NOAA) at the Mauna Loa Observatory, Hawaii [21], and $a(-b)$ denotes $a \times 10^{-b}$.

For reaction (25),

$$
K_{1}=\frac{\left[\mathrm{H}^{+}\right]\left[\mathrm{HCO}_{3}^{-}\right]}{\left[\mathrm{CO}_{2}\right]}=9.747(-7) .
$$

For reaction (26),

$$
K_{2}=\frac{\left[\mathrm{H}^{+}\right]\left[\mathrm{CO}_{3}^{2-}\right]}{\left[\mathrm{HCO}_{3}^{-}\right]}=8.501(-10) .
$$

For reaction (27),

$$
K_{\mathrm{W}}=\left[\mathrm{H}^{+}\right]\left[\mathrm{OH}^{-}\right]=6.46(-15) .
$$

For reaction (28),

$$
K_{\mathrm{B}}=\frac{\left[\mathrm{H}^{+}\right]\left[\mathrm{B}(\mathrm{OH})_{4}^{-}\right]}{\left[\mathrm{B}(\mathrm{OH})_{3}\right]}=1.881(-9) \text {. }
$$

The alkalinity, $A$, which expresses the electrical neutrality of ocean water is defined as

$$
A=\left[\mathrm{HCO}_{3}^{-}\right]+2\left[\mathrm{CO}_{3}^{2-}\right]+\left[\mathrm{B}(\mathrm{OH})_{4}^{-}\right]+\left[\mathrm{OH}^{-}\right]-\left[\mathrm{H}^{+}\right] .
$$

We can assume that the values of $A$ do not change with time [20]. From (29), we have

$$
\left[\mathrm{CO}_{2}\right]=K_{0} P_{t}
$$

From (30) and (35), we have

$$
\left[\mathrm{HCO}_{3}^{-}\right]=\frac{K_{1}\left[\mathrm{CO}_{2}\right]}{\left[\mathrm{H}^{+}\right]}=\frac{K_{0} K_{1} P_{t}}{\left[\mathrm{H}^{+}\right]} .
$$

Similarly, we obtain

$$
\left[\mathrm{CO}_{3}^{2-}\right]=\frac{K_{2}\left[\mathrm{HCO}_{3}^{-}\right]}{\left[\mathrm{H}^{+}\right]}=\frac{K_{0} K_{1} K_{2} P_{t}}{\left[\mathrm{H}^{+}\right]^{2}}
$$

from (31) and (36).

Using

$$
B=\left[\mathrm{B}(\mathrm{OH})_{3}\right]+\left[\mathrm{B}(\mathrm{OH})_{4}^{-}\right]
$$

in (33), we have

$$
\left[\mathrm{B}(\mathrm{OH})_{4}^{-}\right]=\frac{B K_{\mathrm{B}}}{K_{\mathrm{B}}+\left[\mathrm{H}^{+}\right]} .
$$

Substituting (32) and (35)-(39) into (34), we have

$$
A=\frac{K_{0} K_{1} P_{t}}{\left[\mathrm{H}^{+}\right]}+\frac{2 K_{0} K_{1} K_{2} P_{t}}{\left[\mathrm{H}^{+}\right]^{2}}+\frac{B K_{\mathrm{B}}}{K_{\mathrm{B}}+\left[\mathrm{H}^{+}\right]}+\frac{K_{\mathrm{W}}}{\left[\mathrm{H}^{+}\right]}-\left[\mathrm{H}^{+}\right]
$$

which simplifies to the solution of a fourth-order polynomial given by

$$
p\left(\left[\mathrm{H}^{+}\right]\right)=\sum_{n=0}^{4} D_{n}\left[\mathrm{H}^{+}\right]^{n}
$$

where

$$
\begin{aligned}
& D_{0}=2 K_{0} K_{1} K_{2} P_{t} K_{\mathrm{B}}, \\
& D_{1}=K_{0} K_{1} P_{t} K_{\mathrm{B}}+2 K_{0} K_{1} K_{2} P_{t}+K_{\mathrm{W}} K_{\mathrm{B}}, \\
& D_{2}=K_{0} K_{1} P_{t}+B K_{\mathrm{B}}+K_{\mathrm{W}}-A K_{\mathrm{B}}, \\
& D_{3}=-K_{\mathrm{B}}-A, \\
& D_{4}=-1 .
\end{aligned}
$$

We use $A=2.050$ [22, p. 334] and $B=0.409$ [20, p. 131].

4.3. Dynamic Behaviour. We next study the dynamic behaviour of the methods in the complex plane $\mathbb{Z}$ to find the best starting points. For a given value of $P_{t}$, polynomial $p\left(\left[\mathrm{H}^{+}\right]\right)$in (41) has one positive real root (the one we are seeking), one negative real root, and two complex roots. Since these solutions have very small values except the negative one, it is difficult to study their polynomiography [23]. Instead, we consider the change of variable

$$
z=\frac{1}{\left[\mathrm{H}^{+}\right]}, \quad z \in \mathbb{Z}
$$

and then the $\mathrm{pH}=\log _{10} z$. We require to find the positive real solution of another fourth-order polynomial:

$$
p(z)=\sum_{n=0}^{4} D_{4-n} z^{n}
$$

We draw the polynomiographs of $p\left(\left[\mathrm{H}^{+}\right]\right)$. Let $z_{0}=x+$ $i y$, and let $x, y \in \mathbb{R}$ be the initial point. A square grid of 65536 points, composed of 256 columns and 256 rows corresponding to the pixels of a computer display, would represent a region of the complex plane [24]. We consider the square $\mathbb{R} \times \mathbb{R}=[-1(9), 1(9)] \times[-1(9), 1(9)]$. Each grid point is used as a starting value $z_{0}$ of the sequence $z_{k+1}=\psi_{\mathrm{IF}}\left(z_{k}\right)$ and the number of iterations until convergence is counted for each grid point. We assign different colours to each root $z_{j}^{*}, j=1,2,3,4$ of $p\left(\left[\mathrm{H}^{+}\right]\right)$if $\left|z_{j}^{*}-z_{k}\right|<1(-4)$, in at most 25 iterations In this way, the basin of attraction for each 


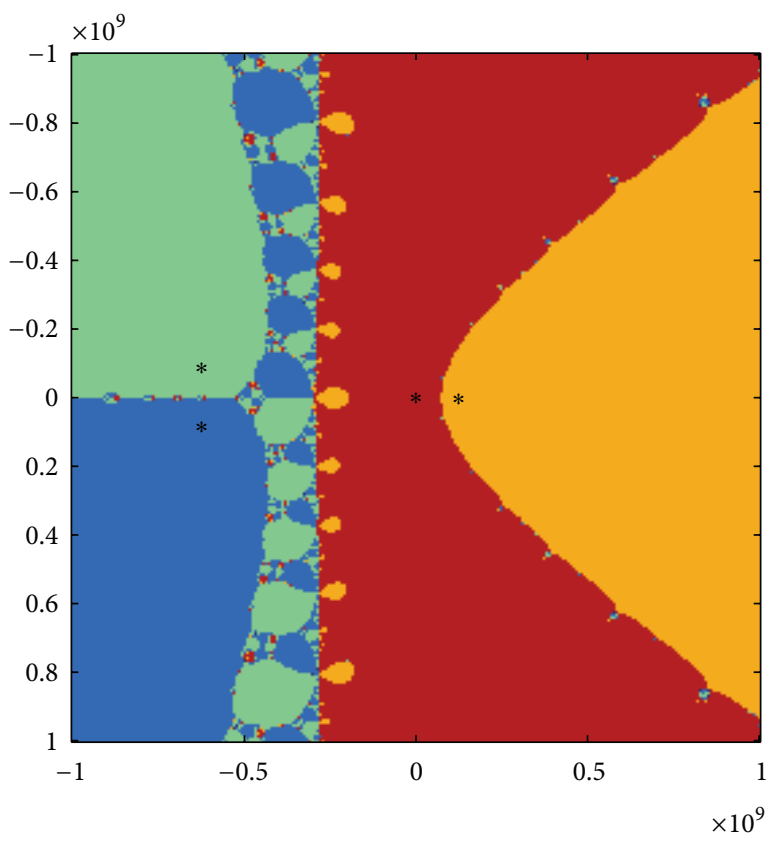

(a) 2nd NR

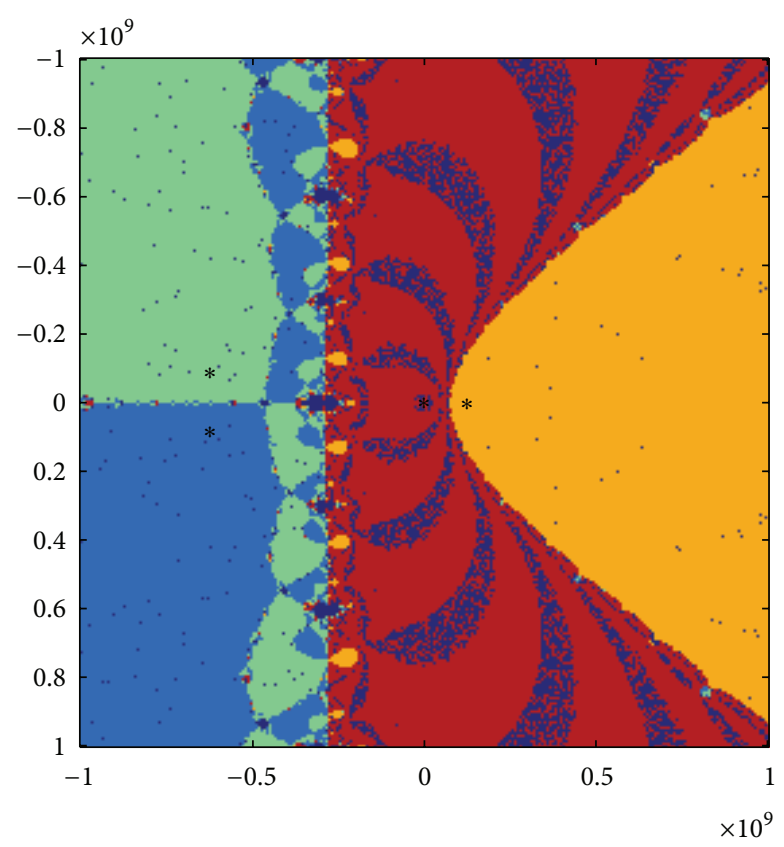

(b) 3rd NS

FIgURE 1: Polynomiographs of the 2nd NR and 3rd NS methods for the polynomial $p(z)$ with $P_{t}=393.81$.

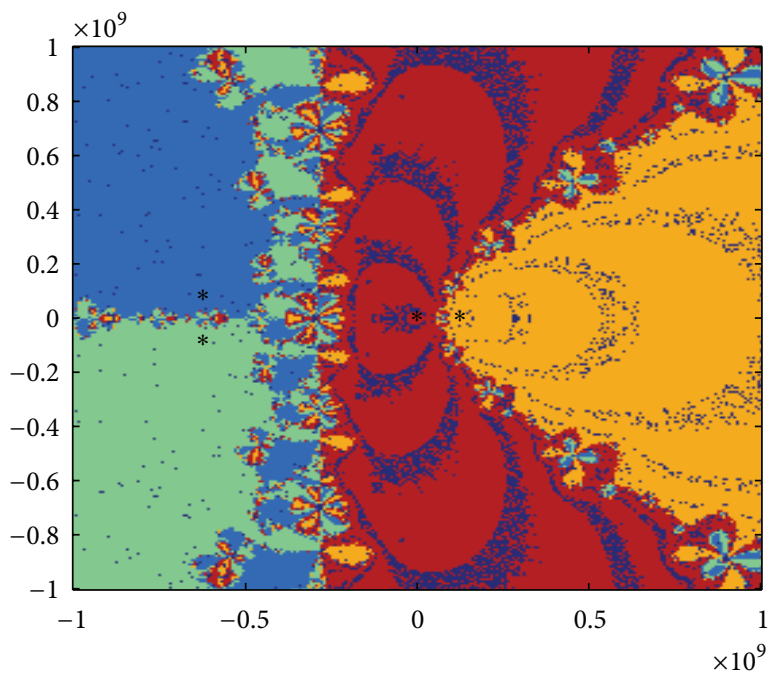

(a) 4th NS

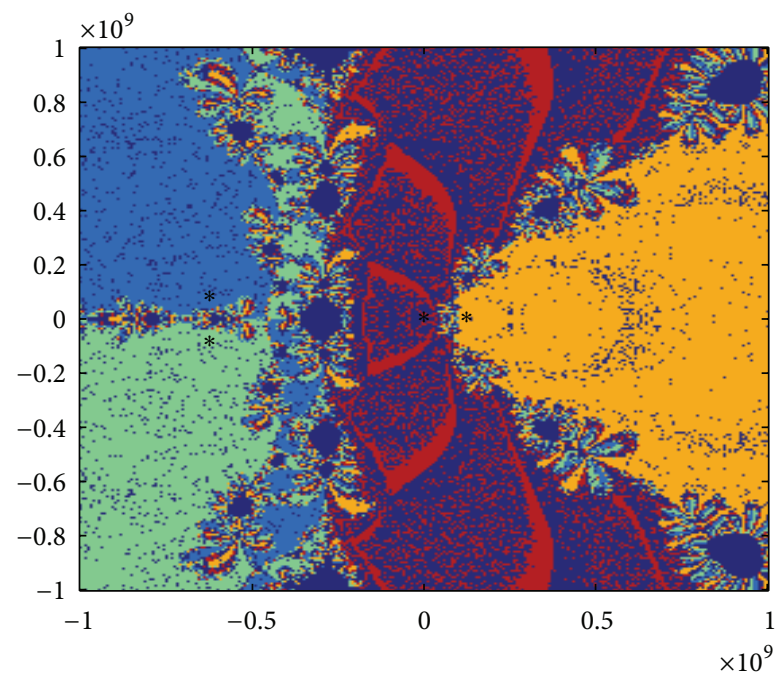

(b) 8th NS

Figure 2: Polynomiographs of the 4th NS and 8th NS methods for the polynomial $p(z)$ with $P_{t}=393.81$.

root would be assigned a characteristic colour. The common boundaries of these basins of attraction constitute the Julia set of the IF If the iterates do not satisfy the above criterion for convergence, we assign the dark blue colour.

Figures 1 and 2 show the polynomiographs of the 2nd NR, 3rd NS, 4th NS and 8th NS methods, respectively. In this case, the positive root of the polynomial, $z^{*}=$ $1.262801212073384(8)$ (coloured brownish yellow), corresponds to the solution $\left[\mathrm{H}^{+}\right]^{*}=7.918902757133942(-9)$. It can be shown that there are diverging points for the higher-order Newton-secant methods and that the 2nd NR method has the largest basins of attraction for the positive root among the 4 methods. But we are using the dynamics of the methods to find a suitable starting point for the higherorder Newton-secant methods so that we can make use of their higher-order convergence. Figures 3 and 4 show the basins of attractions on the real line of the 2nd NR, 3rd NS, 4th NS, and 8th NS methods, respectively, for the positive root of $p(z)$. They reveal that the 2 nd NR will converge for a starting point $z_{0}>0.7(8)$. As the order of the method 


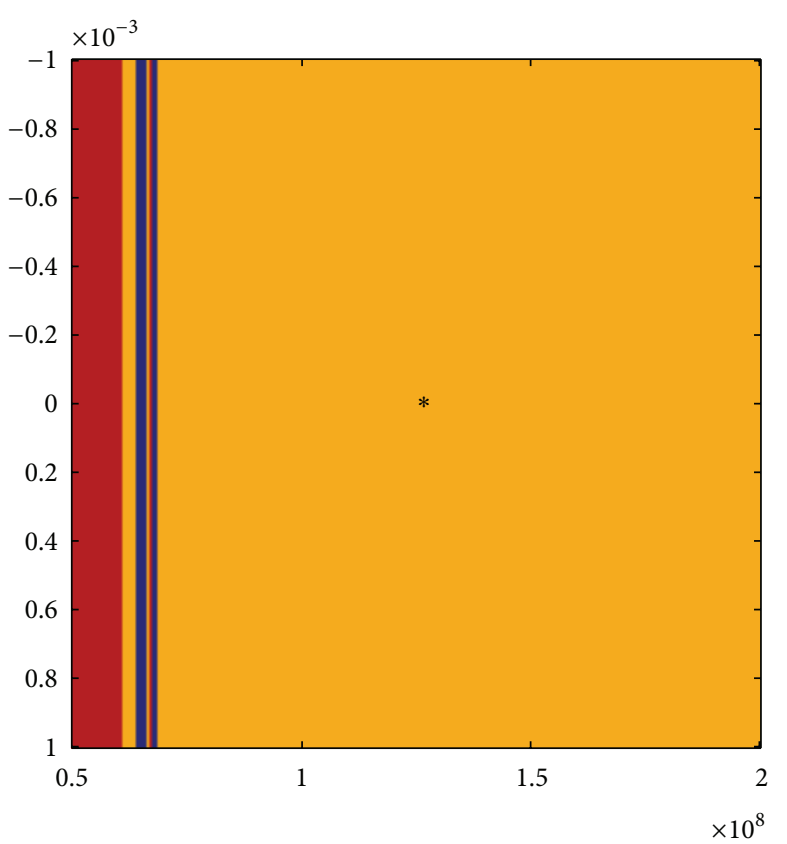

(a) 2nd NR

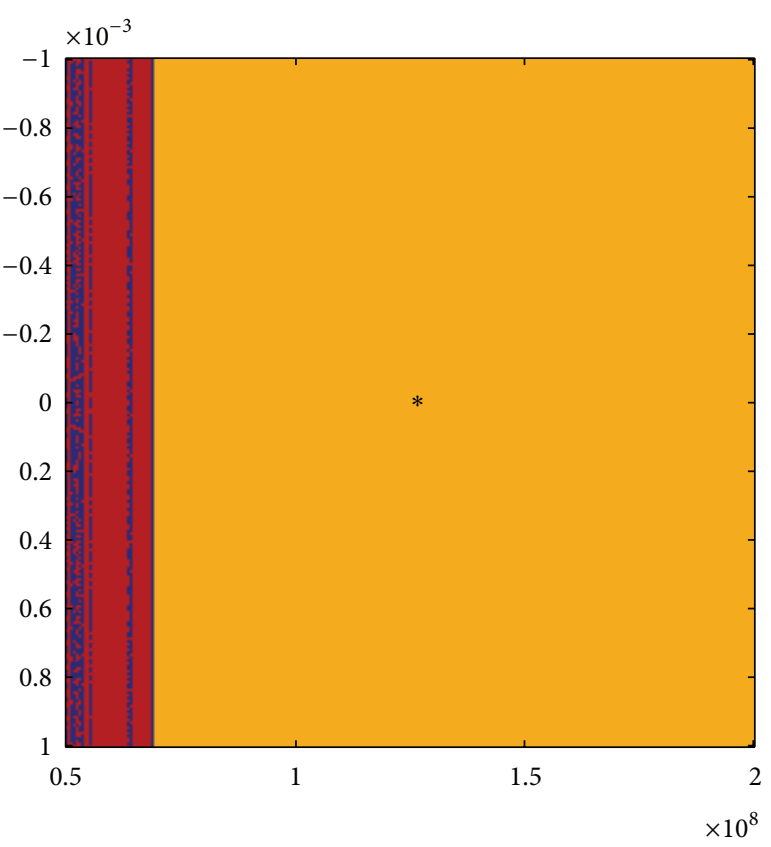

(b) 3rd NS

FIGURE 3: Basins of attractions on the real line of the 2nd NR and 3rd NS methods for the positive root of $p(z)$.

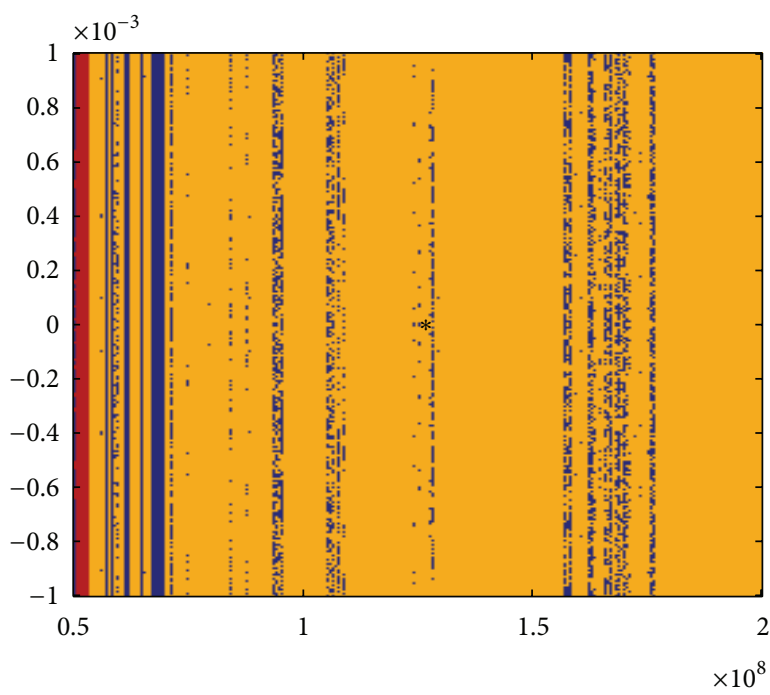

(a) 4th NS

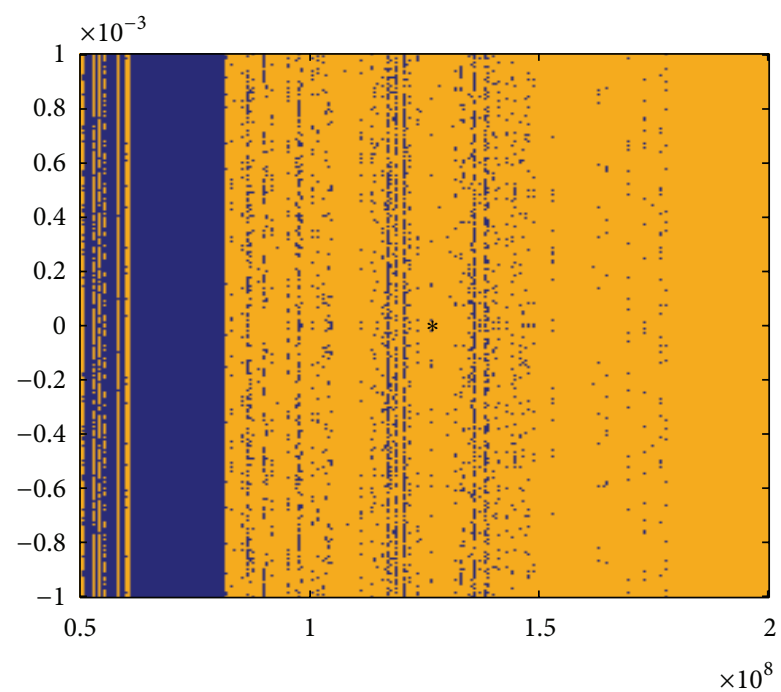

(b) 8th NS

FIgURE 4: Basins of attractions on the real line of the 4th NS and 8th NS methods for the positive root of $p(z)$.

increase, the basins of attraction decrease and higher-order Newton-secant methods have difficulty to converge for some starting points. We also find that all methods will converge for the starting point $z_{0}=1.25(8)$ or $\left[\mathrm{H}^{+}\right]_{0}=8(-9)$.

4.4. Numerical Experiments and Results. We use the data available from NOOA to calculate the $\mathrm{pH}$ of the ocean from 1959 to 2012 . We use a common starting point $[\mathrm{H}]_{0}^{+}=8(-9)$ for each $P_{t}$ and stop the methods whenever $\left|[\mathrm{H}]_{k+1}^{+}-[\mathrm{H}]_{k}^{+}\right|<$ $1(-12)$ in at most 25 iterations. The approximate solutions are calculated correctly to 16 digits in MATLAB. We denote by $N_{s}$ the number of successful points and by $\mu$ as the mean iteration number for the converging points. Table 2 gives a comparison in which we observe that the 3 methods successfully converge to the required root but the 8 th NS method has a few diverging points. The 4th NS method is the most effective with the lowest mean iteration number and all converging points. Table 1 shows the calculated $\mathrm{pH}$ from 1959 to 2012. Figure 5 shows the variation of $\mathrm{CO}_{2}$ and $\mathrm{pH}$ with time. We observe that as the $\mathrm{CO}_{2}$ increases, the $\mathrm{pH}$ decreases. 

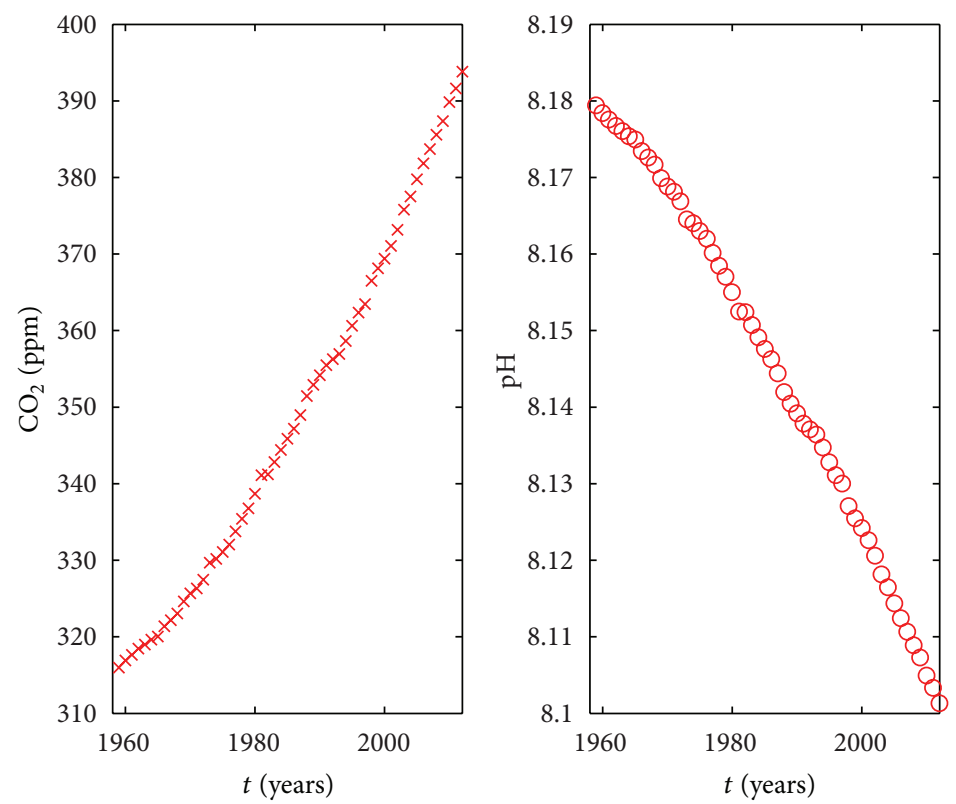

FIGURE 5: Variation of $\mathrm{CO}_{2}$ and $\mathrm{pH}$ with time.

TABLE 1: $\mathrm{pH}$ of oceans using the $P_{t}$ from NOAA from 1959 to 2012.

\begin{tabular}{lccccc}
\hline Time & $P_{t}$ & $\mathrm{pH}$ & Time & $P_{t}$ & $\mathrm{pH}$ \\
\hline 1959 & 315.98 & 8.1794 & 1986 & 347.19 & 8.1463 \\
1960 & 316.91 & 8.1784 & 1987 & 348.98 & 8.1444 \\
1961 & 317.64 & 8.1776 & 1988 & 351.45 & 8.1419 \\
1962 & 318.45 & 8.1767 & 1989 & 352.90 & 8.1405 \\
1963 & 318.99 & 8.1761 & 1990 & 354.16 & 8.1392 \\
1964 & 319.62 & 8.1754 & 1991 & 355.48 & 8.1379 \\
1965 & 320.04 & 8.1749 & 1992 & 356.27 & 8.1371 \\
1966 & 321.38 & 8.1735 & 1993 & 356.95 & 8.1364 \\
1967 & 322.16 & 8.1726 & 1994 & 358.64 & 8.1347 \\
1968 & 323.04 & 8.1717 & 1995 & 360.62 & 8.1328 \\
1969 & 324.62 & 8.1699 & 1996 & 362.36 & 8.1311 \\
1970 & 325.68 & 8.1688 & 1997 & 363.47 & 8.1300 \\
1971 & 326.32 & 8.1681 & 1998 & 366.50 & 8.1270 \\
1972 & 327.45 & 8.1669 & 1999 & 368.14 & 8.1254 \\
1973 & 329.68 & 8.1645 & 2000 & 369.40 & 8.1242 \\
1974 & 330.17 & 8.1640 & 2001 & 371.07 & 8.1226 \\
1975 & 331.08 & 8.1630 & 2002 & 373.17 & 8.1206 \\
1976 & 332.05 & 8.1620 & 2003 & 375.78 & 8.1181 \\
1977 & 333.78 & 8.1602 & 2004 & 377.52 & 8.1165 \\
1978 & 335.41 & 8.1584 & 2005 & 379.76 & 8.1144 \\
1979 & 336.78 & 8.1570 & 2006 & 381.85 & 8.1124 \\
1980 & 338.68 & 8.1550 & 2007 & 383.71 & 8.1107 \\
1981 & 341.11 & 8.1525 & 2008 & 385.57 & 8.1089 \\
1982 & 341.22 & 8.1524 & 2009 & 387.35 & 8.1073 \\
1983 & 342.84 & 8.1507 & 2010 & 389.85 & 8.1050 \\
1984 & 344.41 & 8.1491 & 2011 & 391.62 & 8.1033 \\
1985 & 345.87 & 8.1476 & 2012 & 393.81 & 8.1013 \\
\hline & & & & & \\
1954 &
\end{tabular}

TABLE 2: Comparison of successful starting point and mean iteration number for each method.

\begin{tabular}{lcc}
\hline Method & $N_{s}$ & $\mu$ \\
\hline 2nd NR & 54 & 3.7037 \\
3th NS & 54 & 2.8704 \\
4th NS & 54 & 2.7778 \\
8th NS & 47 & 2.1852 \\
\hline
\end{tabular}

TABLE 3: Unit root tests.

\begin{tabular}{lcccc}
\hline & \multicolumn{2}{c}{ ADF } & \multicolumn{2}{c}{ DF-GLS } \\
Series & $\begin{array}{c}\text { With } \\
\text { constant and } \\
\text { without trend }\end{array}$ & $\begin{array}{c}\text { With } \\
\text { constant and } \\
\text { with trend }\end{array}$ & $\begin{array}{c}\text { With } \\
\text { constant and } \\
\text { without trend }\end{array}$ & $\begin{array}{c}\text { With } \\
\text { constant } \\
\text { and } \\
\text { with trend }\end{array}$ \\
\hline $\log _{10} \mathrm{pH}$ & $3.412[0]$ & $-1.800[0]$ & $-0.121[4]$ & $-0.147[1]$ \\
$\log _{10} \mathrm{CO}_{2}$ & $3.266[0]$ & $-1.894[0]$ & $-0.130[4]$ & $-0.188[1]$ \\
$\Delta \log _{10} \mathrm{pH}$ & $-2.291[3]$ & $-6.104[1]^{*}$ & $-2.352[2]^{* *}$ & $-4.486[1]^{*}$ \\
$\Delta \log _{10} \mathrm{CO}_{2}$ & $-2.347[3]$ & $-6.101[1]^{*}$ & $-2.423[2]^{* *}$ & $-6.241[1]^{*}$ \\
\hline
\end{tabular}

Note: to select the order of lag, we start with a maximum lag length of 4 and pare it down as per the Akaike information criterion (AIC). There is no general rule on how to choose the maximum lag to start with. The bandwidth and maximum lag length are chosen according to the Bartlett kernel which is equal to $4(T / 100)^{2 / 9} \approx 4$, where $T=54$. The optimal lag length is given in square brackets. The MacKinnon critical values [10] for the ADF unit root tests with a constant and without a time are $-3.59,-2.94$, and -2.60 at $1 \%$, $5 \%$, and $10 \%$ significance level,respectively, while those with a constant and a time trend are $-4.17,-3.51$, and -3.19 , respectively. DF-GLS critical values without trend at $1 \%, 5 \%$, and $10 \%$ levels are $-2.62,-2.26$, and -1.95 and with a trend are $-3.76,-3.17$, and -2.87 , respectively. The optimal lag is chosen according to the Akaike information criterion (AIC) and Schwarz Bayesian criterion for the ADF and DF-GLS tests, respectively. ${ }^{*}$ and ${ }^{* *}$ denote $1 \%$ and $5 \%$ significance level correspondingly. 
TABLE 4: Johansen cointegration test.

\begin{tabular}{lccccc}
\hline \multirow{2}{*}{ LR test } & \multicolumn{2}{c}{ Hypothesis } & Statistics & 95\% critical values & 90\% critical values \\
& Null & Alternative & $23.752^{* *}$ & 18.330 & 16.280 \\
$\lambda$ - $\max$ & $r=0$ & $r=1$ & 4.773 & 11.540 & 9.750 \\
\hline $\operatorname{Tr}$ & $r \leq 1$ & $r=2$ & $28.525^{* *}$ & 23.830 & 21.230 \\
& $r=0$ & $r \geq 1$ & 4.773 & 11.540 & 9.750 \\
\hline
\end{tabular}

Note: the test is conducted with unrestricted constants and trends in the VAR model. $r$ is the number of cointegrating vectors. The optimal lag length is set to 4 according to the AIC.

4.5. Empirical Analysis of Impact of $\mathrm{CO}_{2}$ on Alkalinity of Seawater. To empirically test the impact of $\mathrm{CO}_{2}$ in the atmosphere on the alkalinity of seawater, we set up the following generalized equation:

$$
\mathrm{pH}=f\left(\mathrm{CO}_{2}, \epsilon\right),
$$

where $\epsilon$ is the error term. The concept of cointegration as per Engle and Granger [25] is used to investigate any long-run relationship between nonstationary variables. Time-series data such as $\mathrm{pH}$ and $\mathrm{CO}_{2}$ tend to be nonstationary in levels. If a series is stationary, then the probability laws controlling its process are stable over time, that is, in statistical equilibrium [26]. In contrast, series having a unit root are nonstationary. Shocks have a unit root and can, in part, change the long-run level of the time series permanently. Per se, a series is said to be integrated of order $v$ or $I(v)$ if it were to be different by $v$ times to become stationary. A stationary process is a series which follows an $I(0)$ process. To run the model, the logarithm of base 10 of the variables is taken. As a prerequisite of the cointegration test, the unit root properties of the two series are investigated. The augmented Dickey-Fuller (ADF) test as proposed by Dickey and Fuller [27] and the DFGLS test as per Elliott et al. [28] for the null of a unit root are considered. The DF-GLS test is a modified ADF test and tends to be a more asymptotically powerful test. These tests apply regressions which include a constant term only, while the other contain both a constant term and a time trend. Time series data tend to exhibit a trend over time and hence it is more appropriate to consider a regression with both a constant term and a trend. In contrast, first differencing is likely to remove any deterministic trends. Hence, the regression should include a constant only. In general, time-series data tends to be nonstationary and $I(1)$. Both series must be integrated of the same order to validate a cointegrating relationship. The Johansen cointegration test [29] is conducted within a vector autoregression (VAR) structure and it involves two log-likelihood ratio (LR) test statistics, namely, the maximum eigenvalue $(\lambda$-max) and trace $(\mathrm{Tr})$ statistics. Once a cointegrating relationship is established, long-run estimates can be computed via the fully modified ordinary least squares (FMOLS) and dynamic OLS (DOLS) of Phillips and Hansen [30] and Stock and Watson [31], respectively. Table 3 shows the results of the unit root tests. Both series are found to be nonstationary. The ADF test statistics illustrate an $I(1)$ process for both series only when a trend is considered in the testing framework. However, when testing for a unit root using first-differenced
TABLE 5: Long-run estimators.

\begin{tabular}{lcccc}
\hline \multirow{2}{*}{ Series } & \multicolumn{3}{c}{ Dependent $\log _{10} \mathrm{pH}$} \\
& Coefficient & $\begin{array}{c}\text { Standard } \\
\text { deviation }\end{array}$ & Coefficient & $\begin{array}{r}\text { Standard } \\
\text { deviation }\end{array}$ \\
\hline $\log _{10} \mathrm{CO}_{2}$ & $-0.845^{*}$ & 0.003 & $-0.849^{*}$ & 0.009 \\
\hline
\end{tabular}

Note: a constant and time trend are included in each model. The critical values of the two-tailed $t$-statistics test at $1 \%, 5 \%$, and $10 \%$ significance levels are $2.326,1.645$, and 1.282 , respectively. The maximum lag/lead is set to 2 [11].

data, the trend should be excluded. The DF-GLS confirms our a priori expectation. Both series are found to be $I(1)$ for both deterministics. Table 4 reports the cointegration test statistics. According to the null hypothesis for the $\lambda$-max and Tr tests, there are at most $r$ cointegrating vectors, whereas the alternative hypotheses are $r+1$ and at least $r+1$ for the $\lambda$-max and $\operatorname{Tr}$ statistics, respectively. As per the $\lambda$-max statistics, the null hypothesis of $r=0$ is rejected in favour of $r=1$. A similar result is found when referring to the $\operatorname{Tr}$ statistics as the null hypothesis of $r=0$ is rejected in favour of $r \geq 1$. The computed test statistics are 23.75 and 28.53 for the $\lambda$-max and Tr tests, respectively. The null hypothesis of no cointegration is rejected at $5 \%$ level. Furthermore, the null hypothesis of at most one cointegrating vector $(r \leq 1)$ is in no case rejected in both cases. In sum, these findings provide evidence of a long-run equilibrium relationship between $\mathrm{pH}$ and $\mathrm{CO}_{2}$. Given the presence of a cointegrating vector, the long-run elasticity can now be computed and is reported in Table 5. The FMOLS and DOLS methods are robust single equation approaches which can correct for endogeneity bias and serial correlation (The computed test statistic for serial correlation according to Durbin and Watson [32] is $d$-statistic $(2,54)=0.021$. This reveals positive serial correlation) in a semiparametric and parametric way, respectively. $\mathrm{CO}_{2}$ in the atmosphere has a statistically significant negative impact on the alkalinity of seawater and the long-run elasticities from both methods tend to coincide. For instance, a one-percent increase in $\mathrm{CO}_{2}$ emissions will generate to a reduction in seawater alkalinity of 0.85 percent in the long run.

\section{Conclusion}

We develop an optimal fourth- and eighth-order Newtonsecant methods. We study their dynamics in a fourth-order polynomial arising in ocean acidification. We also perform an 
investigation on the long-run implications of $\mathrm{CO}_{2}$ emissions on alkalinity of seawater using fully modified ordinary least squares (FMOLS) and dynamic OLS (DOLS). We find that a one-percent increase in $\mathrm{CO}_{2}$ emissions will lead to a reduction in seawater alkalinity of 0.85 percent in the long run. Put differently, a fall in $\mathrm{CO}_{2}$ emissions will lead to an improvement of the quality of seawater and therefore to the sustainability of the marine ecosystem.

\section{Acknowledgments}

The authors are thankful to Pieter Tans for giving the permission to use the data published by the National Oceanic and Atmospheric Administration (NOAA). The authors are thankful to Robert Lundmark and Patrik Söderholm for their valuable suggestions and comments on the paper. The authors are also thankful to the unknown referees for their valuable comments to improve the paper.

\section{References}

[1] J. F. Traub, Iterative Methods for the Solution of Equations, Prentice Hall, New Jersey, NJ, USA, 1964.

[2] D. K. R. Babajee, Analysis of higher order variants of Newton's method and their applications to differential and integral equations and in ocean acidification [Ph.D. thesis], University of Mauritius, 2010.

[3] A. B. Kasturiarachi, "Leap-frogging Newton's method", International Journal of Mathematical Education in Science and Technology, vol. 33, no. 4, pp. 521-527, 2002.

[4] R. Wait, The Numerical Solution of Algebraic Equations, John Wiley \& Sons, 1979.

[5] A. M. Ostrowski, Solutions of Equations and System of Equations, Academic Press, New York, NY, USA, 1960.

[6] H. T. Kung and J. F. Traub, "Optimal order of one-point and multipoint iteration," Journal of the Association for Computing Machinery, vol. 21, no. 4, pp. 643-651, 1974.

[7] D. K. R. Babajee and M. Z. Dauhoo, "An analysis of the properties of the variants of Newton's method with third order convergence," Applied Mathematics and Computation, vol. 183, no. 1, pp. 659-684, 2006.

[8] R. F. King, "A family of fourth order methods for nonlinear equations," SIAM Journal on Numerical Analysis, vol. 10, no. 5, pp. 876-879, 1973.

[9] D. K. R. Babajee and R. Thukral, "On a 4-point sixteenth-order king family of iterative methods for solving nonlinear equations," International Journal of Mathematics and Mathematical Sciences, vol. 2012, Article ID 979245, 13 pages, 2012.

[10] J. G. McKinnon, “Critical values for cointegration tests," in Long Run Relationships: Reading in Cointegration, pp. 1-16, Oxford University Press, 1991.

[11] N. C. Mark and D. Sul, "Cointegration vector estimation by panel DOLS and long-run money demand," Oxford Bulletin of Economics and Statistics, vol. 65, no. 5, pp. 655-680, 2003.

[12] P. J. Bresnahan, G. W. Griffiths, A. J. McHugh, and W. E. Schiesser, An Introductory Global $\mathrm{CO}_{2}$ Model. Personal Communication, 2009, http://www.lehigh.edu/ wes1/co2/model.pdf.
[13] G. W. Griffiths, A. J. McHugh, and W. E. Schiesser, "An introductory global $\mathrm{CO}_{2}$ model," Chemical and Biochemical Engineering Quarterly, vol. 22, no. 2, p. 265, 2008.

[14] K. Caldeira and M. E. Wickett, "Oceanography: anthropogenic carbon and ocean pH," Nature, vol. 425, p. 365, 2003.

[15] J. C. Orr, V. J. Fabry, O. Aumont et al., "Anthropogenic ocean acidification over the twenty-first century and its impact on calcifying organisms," Nature, vol. 437, no. 7059, pp. 681-686, 2005.

[16] N. L. Bindo, J. Willebrand, V. Artale et al., "Observations: oceanic climate change and sea level," in Climate Change 2007: The Physical Science Basis. Contribution of Working Group I to the Fourth Assessment Report of the Intergovernmental Panel on Climate Change, S. Solomon, D. Qin, M. Manning et al., Eds., pp. 385-432, Cambridge University Press, New York, NY, USA, 2007.

[17] S. C. Doney and N. M. Levine, How Long Can the Ocean Slow Global Warming? Oceanus, 2006, https://www.whoi.edu/ oceanus/viewArticle.do?id=17726.

[18] T. S. Garrison, Oceanography: An Invitation to Marine Science, Thomson Brooks, 2004.

[19] J. B. Ries, A. L. Cohen, and D. C. McCorkle, "Marine calcifiers exhibit mixed responses to $\mathrm{CO}_{2}$-induced ocean acidification," Geology, vol. 37, no. 12, pp. 1131-1134, 2009.

[20] R. Bacastow and C. D. Keeling, "Atmospheric carbon dioxide and radiocarbon in the natural carbon cycle: changes from a.d. 1700 to 2070 as deduced from a geochemical model," in Proeedings of the 24th Brookhaven Symposium in Biology, G. W. Woodwell and E. V. Pecan, Eds., pp. 86-133, The Technical Information Center, Office of Information Services, United State Atomic Energy Commission, Upton, NY, USA, May 1972.

[21] P. Tans, Trends in carbon dioxide. National Oceanic and Atmospheric Administration Earth System Research Laboratory, 2009, http://www.esrl.noaa.gov/gmd/ccgg/trends/.

[22] J. L. Sarmiento and N. Gruber, Ocean Biogeochemical Dynamics, Princeton University Press, Princeton, NJ, USA, 2006.

[23] B. Kalantari, Polynomial Root-Finding and Polynomiography, World Scientific Publishing, Singapore, 2009.

[24] E. R. Vrscay, "Julia sets and mandelbrot-like sets associated with higher order Schröder rational iteration functions: a computer assisted study," Mathematics of Computation, vol. 46, no. 173, pp. 151-169, 1986.

[25] R. F. Engle and C. W. J. Granger, "Cointegration and errorcorrection: representation, estimation and testing," Econometrica, vol. 55, no. 2, pp. 251-276, 1978.

[26] W. Vandaele, Applied Time Series and Box-Jenkins Models, Academic Press, New York, NY, USA, 1983.

[27] D. A. Dickey and W. A. Fuller, "Likelihood ratio statistics for autoregressive time series with a unit root," Econometrica, vol. 49, no. 4, pp. 1057-1072, 1981.

[28] G. Elliott, T. J. Rothenberg, and J. H. Stock, "Efficient tests for an autoregressive unit root," Econometrica, vol. 64, no. 4, pp. 813836, 1996.

[29] S. Johansen, "Statistical analysis of cointegration vectors," Journal of Economic Dynamics and Control, vol. 12, no. 2-3, pp. 231254, 1988.

[30] P. C. B. Phillips and B. Hansen, "Statistical inference in instrumental variables regression with $\mathrm{i}(1)$ processes," Review of Economic Studies, vol. 57, no. 1, pp. 99-125, 1990. 
[31] J. H. Stock and M. K. Watson, "Testing for common trends," Journal of the American Statistical Association, vol. 83, no. 404, pp. 1097-1107, 1988.

[32] J. Durbin and G. S. Watson, "Testing for serial correlation in least squares regression. I., Biometrika, vol. 37, no. 3-4, pp. 409428, 1950. 


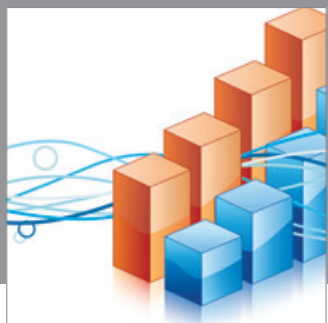

Advances in

Operations Research

mansans

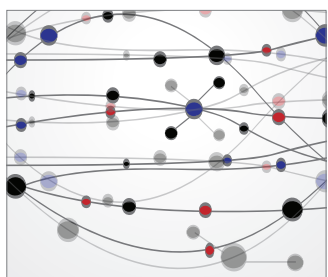

The Scientific World Journal
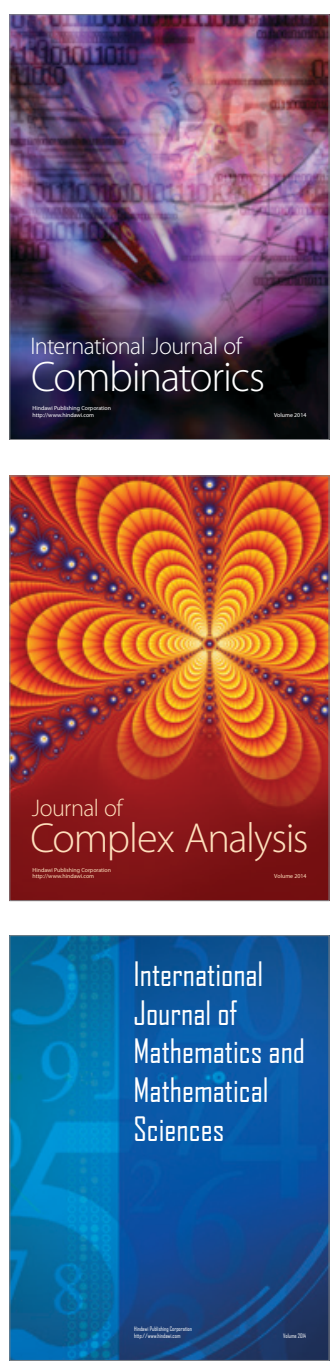
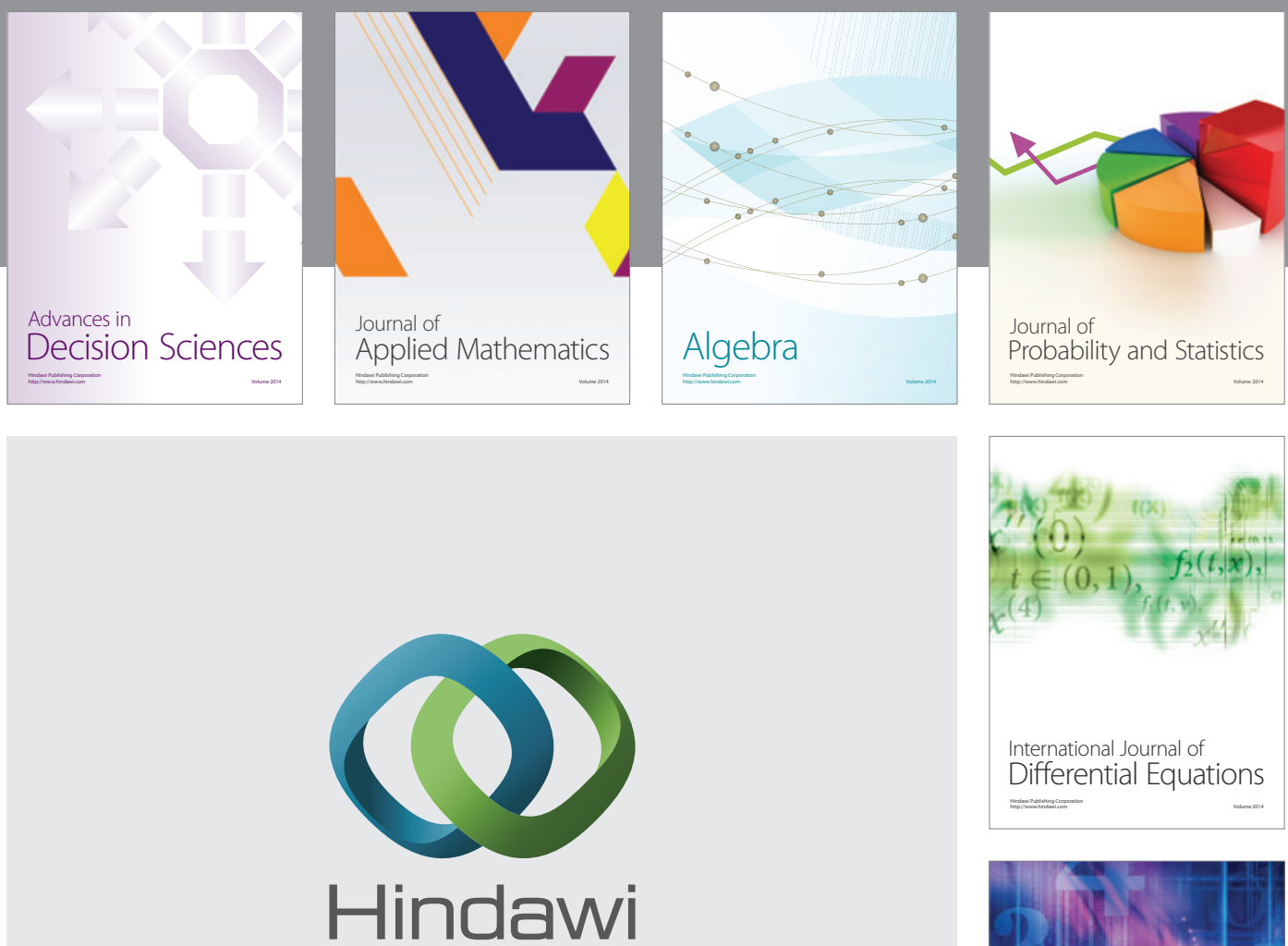

Submit your manuscripts at http://www.hindawi.com
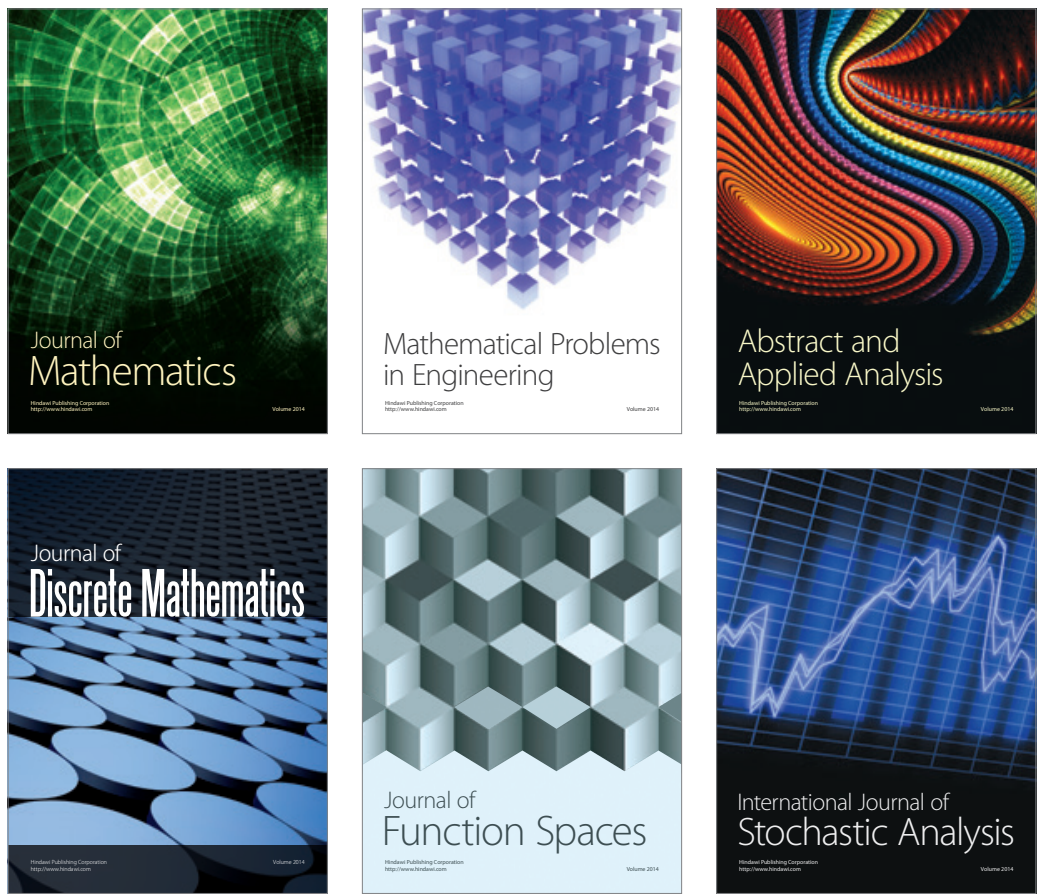

Journal of

Function Spaces

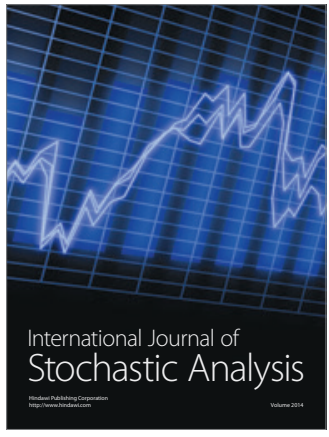

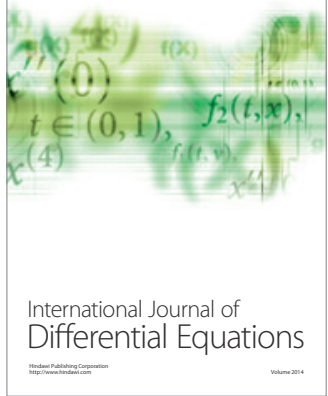
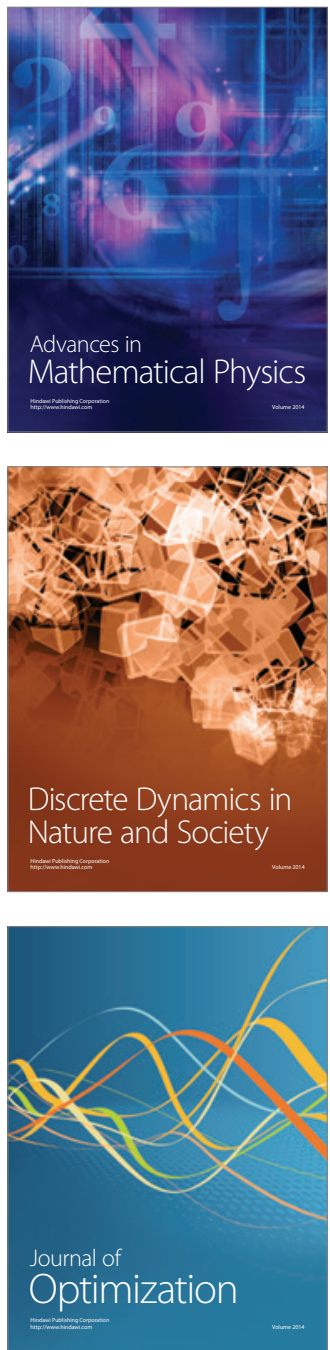